\title{
Monitoring Workloads of a Professional Female Futsal Team over a Season: A Case Study
}

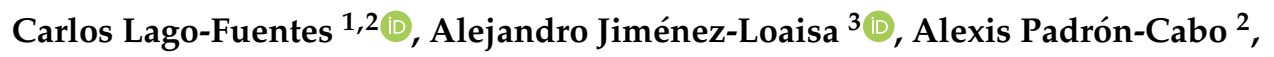 \\ Marián Fernández-Villarino ${ }^{2}$, Marcos Mecías-Calvo 1,4,*(D), Bruno Travassos 5,6,7 (D) \\ and Ezequiel Rey ${ }^{2}$ (D) \\ 1 Facultad de Ciencias de la Salud, Universidad Europea del Atlántico, 39011 Santander, Spain; \\ carlos.lago@uneatlantico.es \\ 2 Faculty of Sports and Education Sciences, Universidad de Vigo, 36005 Pontevedra, Spain; \\ alexiscabo03@gmail.com (A.P.-C.); marianfv@uvigo.es (M.F.-V.); zequirey@uvigo.es (E.R.) \\ 3 Department of Sport Sciences, Sport Research Centre, University Miguel Hernández, 03202 Elche, Spain; \\ alejandro.jimenezl@umh.es \\ 4 Centro de Investigación y Tecnología Industrial de Cantabria (CITICAN), 39011 Santander, Spain \\ 5 Departament of Sport Sciences, Universidade da Beira Interior, 6201-001 Covilhã, Portugal; bfrt@ubi.pt \\ 6 Research Centre in Sports, Health and Human Development, CIDESD, 6201-001 Covilhã, Portugal \\ 7 Portugal Football School, Portuguese Football Federation, 2784-214 Oeiras, Portugal \\ * Correspondence: marcos.mecias@uneatlantico.es; Tel.: +32-942-244-244
}

Received: 5 March 2020; Accepted: 15 May 2020; Published: 19 May 2020

\begin{abstract}
The aims of this study were to describe the external and internal workloads in a professional female futsal team during a whole season and to compare workloads during different periods of the season. Ten professional female futsal players (age $22.8 \pm 4.3$ years; $5.1 \pm 2.4$ years of experience; weight $61.9 \pm 7.1 \mathrm{~kg}$; height $1.66 \pm 0.06 \mathrm{~m}$ ) participated voluntarily in this study during the whole season. The internal workload was measured by the session-Rate of perceived exertion (session-RPE) method, while the external workload was indirectly measured by considering the training and match volume and the type of contents of each session over 43 weeks. Mean sRPE throughout the season was $319.9 \pm 127.1$ arbitrary units (AU). Higher internal loads (total weekly training load and strain) were reported during the pre-season compared with the in-season mesocycles $(p<0.05)$; meanwhile, the fifth to eighth mesocycles of the in-season showed an oscillatory pattern. Finally, Monday was the most-demanding session during the in-season period over the Thursday ( $p<0.05$; effect size: 1.33 ) followed by match day, meanwhile no statistical differences were reported during different sessions of the pre-season microcycle $(p>0.05)$. This study suggests that microcycles of pre-season present a stable load pattern, meanwhile workloads during the in-season period report a tapering strategy in a professional female futsal team.
\end{abstract}

Keywords: team sports; women; session-RPE; performance

\section{Introduction}

The popularity of futsal has been increasing around the world over the last fifteen years [1]. In fact, two new international tournaments have been recently approved by Fédération Internationale de Football Association (FIFA) and Union of European Football Associations (UEFA), as the Youth Olympic Games (both in male and female categories) and the European Female Futsal Cup to promote the development of this sport worldwide. Despite this global growth projection, only a few studies have been published in male futsal, and fewer in female futsal. Therefore, there is a need to investigate the training processes and the methods used by the technical staff to better understand the dynamics of futsal. 
The training process is the best way for modulating athletes' performance during the season [2]. Among other physical capabilities, it may help to increase strength, power, speed and endurance performance according to game demands. However, excessive amounts of training without sufficient recovery can be harmful for performance and injury risk [3]. In the same way, insufficient training can reduce the performance capabilities of one athlete or the whole team [2]. Thus, the development of monitoring and control strategies of sessions with an emphasis on the analysis of the workloads might be relevant for improving sports performance and to reduce the injury risk along the season. Usually, team sports workloads (both training and competition ones) are split into external and internal loads. The main external loads registered are: volume, distance covered, speed thresholds, accelerations and decelerations, while the most common internal loads are: oxygen uptake, heart rate, blood lactate, muscle load or ratings of perceived exertion (RPE) [2].

Several studies in futsal have analysed workloads using some of the aforementioned variables, such as heart rate, lactate, ventilatory threshold or heart rate variability in elite futsal players $[4,5]$. However, the most commonly used tool to measure training load in futsal is session-RPE (sRPE) [6-9], which has been shown to have acceptable reliability and internal consistency [10].

Analyses of the training load over a complete season in professional futsal players have shown large variations, particularly with a decrease of loads during the second half of the season [11,12]. Also, different patterns were registered during the pre-season in comparison with the in-season [8]. Likewise, other studies have found an inverse correlation among a lower RPE and higher performance levels in U20 professional futsal players [7]. However, these data exist only in male futsal players. Recently, Clemente and Nikolaidis [13] analysed the differences in training loads between sexes and sports (soccer and futsal), reporting higher intensity training loads in futsal than in soccer, but without differences among male and female futsal teams, although the female futsal team involved in that study competed in an amateur league and only four weeks of the in-season period were registered. With regard to this, it can be shown that several questions are needed to answer about the workload profile in professional female futsal teams. Taking into account the relevance of applying appropriate workloads to each sport modality and teams to improve physical performance and reduce injury risks, there is a need to analyse the workloads in a professional female futsal team due to the lack of scientific knowledge in this modality. In fact, to our knowledge, no previous studies have registered the workloads in a professional female futsal team during a whole season and compared the load profiles of a standard week of pre-season and in-season. Therefore, the aims of this study were: (i) to analyse and describe the external and internal workloads in a professional female futsal team during a whole season; (ii) to compare workloads during different periods of the season and, (iii) to describe and compare the load profile of a typical week during pre-season and in-season periods.

\section{Materials and Methods}

\subsection{Study Design}

This study followed a descriptive and prospective longitudinal approach over 43 weeks. Before starting the season, the project was presented to the technical staff of the team to be involved in the study, following by the players, who were informed of the study purposes and gave their informed consent. All research was carried out in accordance to the Declaration of Helsinki. The Investigational Review Committee of the Department of Physical Education and Sport Sciences of a Spanish university approved the research.

\subsection{Participants}

Thirteen professional female futsal players competing in the Spanish First Division Futsal League participated voluntarily in this study. Finally, three players were excluded because of injury or participating in less than $90 \%$ of sessions according to previous research [14], so ten players were fully registered (age $22.8 \pm 4.3$ years; $5.1 \pm 2.4$ years of experience; weight $61.9 \pm 7.1 \mathrm{~kg}$; height $1.66 \pm$ 
$0.06 \mathrm{~m}$; body mass index $22.3 \pm 1.4 \mathrm{~kg} / \mathrm{m}^{2}$ ). This team was playing in First Division for the first time, finishing 9th at the end of the season, and two players were called up to play for the Spanish National Team. Players had 5-6 weekly training sessions during the in-season with the team (7.2 $\pm 0.9 \mathrm{~h} /$ week). The team also played one official match per week during the in-season period.

\subsection{Procedures}

The external load was measured by the sum of training and match volume. The training volume was measured by the staff every training session by a chronometer, including the minutes of warm-up [13]. Player exposure during competition was also measured, taking into account the maximum of 40 minutes (official duration of futsal matches) [9]. Technical staff registered both data. The training contents were also registered, being classified according to previous scientific evidence in: strength training (exercises in the gym), power and acceleration (exercises done on the court with or without implements), specific endurance (exercises with the goal of improving aerobic and anaerobic power), preventive training (circuits designed to reduce injury risks), technical-tactical (main tasks with technical-tactical goals) and emotive-volitional tasks (exercises aimed at improving group cohesion and teamwork) [11]. Mesocycles (typical length of 5-6 weeks) were classified according to the specific criteria of technical staff in 3 criteria: increasing load (IL), maintenance load (ML) or decreasing load (DL) [15].

The internal load was monitored by the session-RPE (sRPE) method [16] thirty minutes after the end of each session reported on a 10-point RPE scale [5,9]. To reduce possible biases, caution was taken when collecting the scores, trying that the players did not listen to the scores of their teammates [17]. Care was taken to not modify the session routines in order to guarantee the ecological validity of the results [9]. sRPE was designed multiplying RPE by total volume in minutes (obtaining arbitrary units, AU) [10]. The monotony (daily mean split by standard deviation) and the strain (weekly load multiplied by monotony) were also calculated [17]. Total weekly training load (TWTL) was the sum of AU of each week's session [12,14]. Finally, the TWTL of each mesocycle was obtained with the mean of the weeks' TWTL during each mesocycle [7,12].

\subsection{Statistical Analysis}

We tested the assumption of normality using the Kolmogorov-Smirnov test. All variables were distributed normally, except for strain. Descriptive data is presented as mean $(\mathrm{M}) \pm$ standard deviation (SD). Comparisons between daily workloads were analysed using analyses of variance (ANOVA), one for defining the differences among daily workloads during the pre-season and another ANOVA for the same during the in-season period. Differences between eight mesocycles were also calculated using ANOVA, followed by Bonferroni's pairwise comparisons of the means. Effect sizes were calculated regarding differences between daily workloads, with $>0.2,>0.5$, and $>1.2$ being considered to represent small, moderate, and large differences, respectively [18]. All the data were analysed using IBM SPSS for Windows (version 20.0; SPSS Inc., Chicago, IL, USA). Statistical significance was set at $p<0.05$.

\section{Results}

The team played 17,566 minutes (including training sessions and matches) throughout the whole season with $480.2 \pm 121.7$ min per week, split into 157 training sessions, 30 matches of league and six of regional cup. The mean RPE throughout the season was $5.70 \pm 0.64$ and the sRPE, $319.9 \pm 127.1 \mathrm{AU}$. In addition, the TWTL was $2183.81 \pm 838.45 \mathrm{AU}$, and the monotony and strain were around $1.00 \pm 0.32$ and $2419.75 \pm 1961.25$, respectively. Figure 1 presents the mean data about TWTL, monotony and strain throughout the 43 microcycles of the season. 


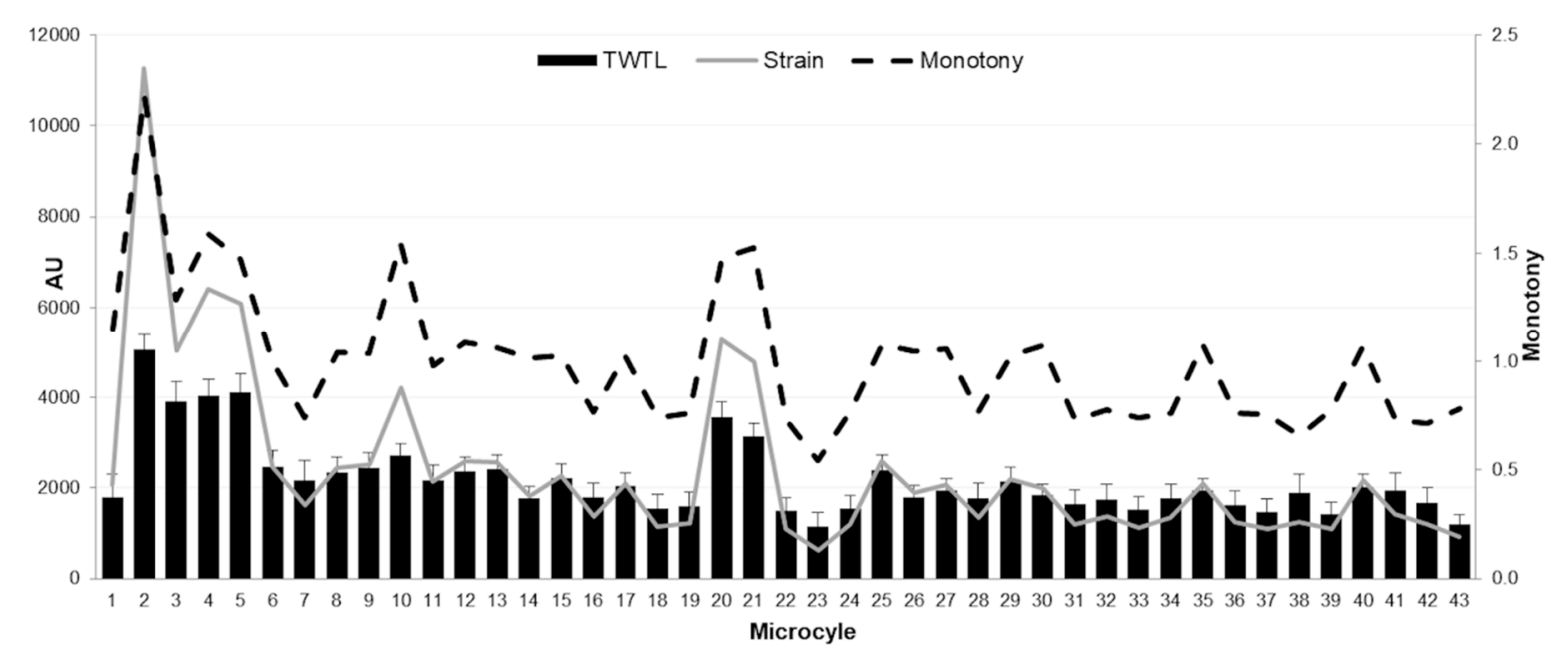

Figure 1. Description of the internal loads of female futsal players in each microcycle over a season. Notes: AU: Arbitrary units; TWTL: total weekly training load.

Figure 2 illustrates the oscillatory pattern throughout the season by comparing the eight different mesocycles. A progressive decreasing load was observed throughout the season, showing significant difference in the TWTL among the first mesocycle and the remaining seven. Differences in the TWTL between the second and fourth mesocycle and the fifth, sixth and seventh were also shown $(p<0.05)$. The contents distribution is also highlighted in Table 1 showing that technical-tactical training volume increased during the eight mesocycles, while conditional training volume (strength, power and specific endurance) decreased along the season.

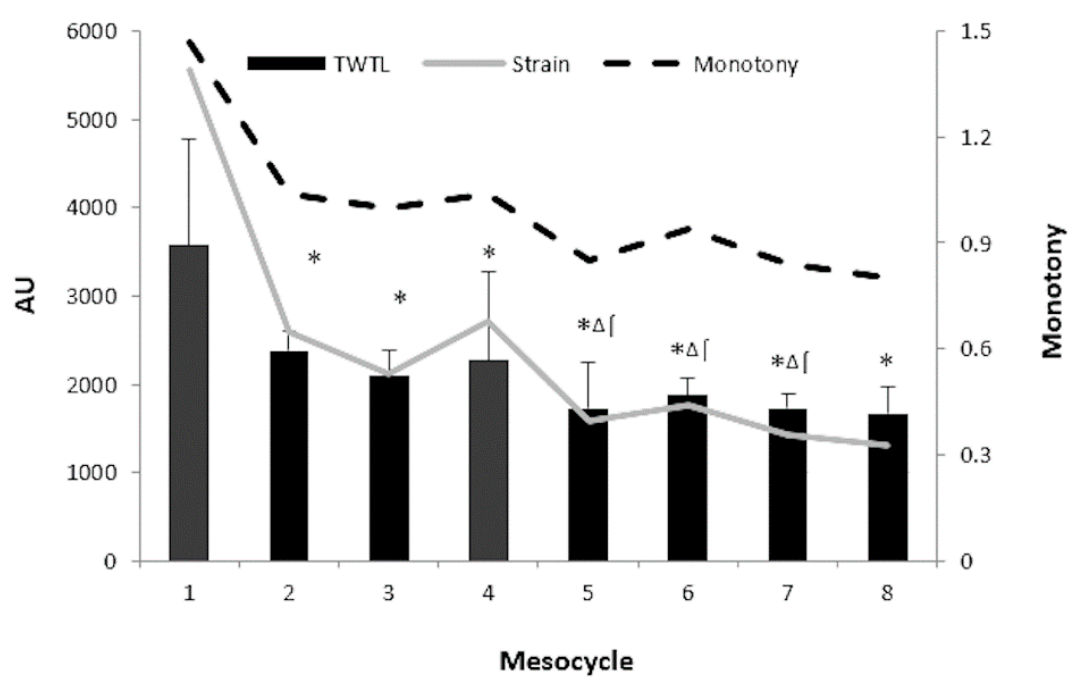

Figure 2. Differences in workloads parameters among mesocycles over the season. Notes: AU: arbitrary units; TWTL: total weekly training load; M1 and 4: preparatory period; $M$ 2, 3, 5, 6, 7, 8: competitive period; * Significant differences between TWTL 1st mesocycle over the rest; I Significant differences between TWTL 2 nd mesocycle over the rest; ${ }^{\Delta}$ Significant differences between TWTL 4 th mesocycle over the rest of mesocycles. 
Table 1. Description of general characteristics in each mesocycle over a season.

\begin{tabular}{ccccccccc}
\hline Mesocycle & $\mathbf{1}$ & $\mathbf{2}$ & $\mathbf{3}$ & $\mathbf{4}$ & $\mathbf{5}$ & $\mathbf{6}$ & $\mathbf{7}$ & $\mathbf{8}$ \\
\hline Type & IL & ML & DL & IL & DL & IL & ML & ML \\
Weeks & 6 & 5 & 7 & 5 & 4 & 5 & 5 & 6 \\
Matches & 7 & 5 & 6 & 1 & 4 & 5 & 5 & 6 \\
Period & PP & CP & CP & PP & CP & CP & CP & CP \\
Strength & 315 & 60 & 70 & 22 & 20 & 30 & 10 & 0 \\
Power & 95 & 105 & 100 & 85 & 85 & 75 & 70 & 60 \\
Specific Endurance & 585 & 145 & 270 & 290 & 80 & 210 & 160 & 125 \\
Preventive & 490 & 480 & 415 & 235 & 245 & 260 & 205 & 305 \\
Technical-Tactical & 1620 & 915 & 1165 & 775 & 860 & 935 & 815 & 1090 \\
Emotive-volitional & 655 & 430 & 515 & 200 & 225 & 275 & 350 & 270 \\
\hline
\end{tabular}

Notes: Contents are represented in minutes. IL: increasing load; ML: maintenance load; DL: decreasing load; TWTL: total weekly training load (in Arbitrary Units); PP: preparatory period; CP: competitive period.

Figure 3 shows the mean weekly internal load presenting weekly periodisation of the pre-season and in-season periods. The weekly periodisation is different in both periods, showing a clearer weekly undulation in the in-season period. Pre-season training sessions are more similar, highlighting the match workload as the most demanding. The weekly periodisation on the in-season showed a higher AU on Saturdays with a decreasing load during the remaining days, showing higher loads on Monday and Tuesday over Thursday $(p<0.001 ; \mathrm{ES}=1.33$ and $p<0.001 ; \mathrm{ES}=0.80$, respectively).

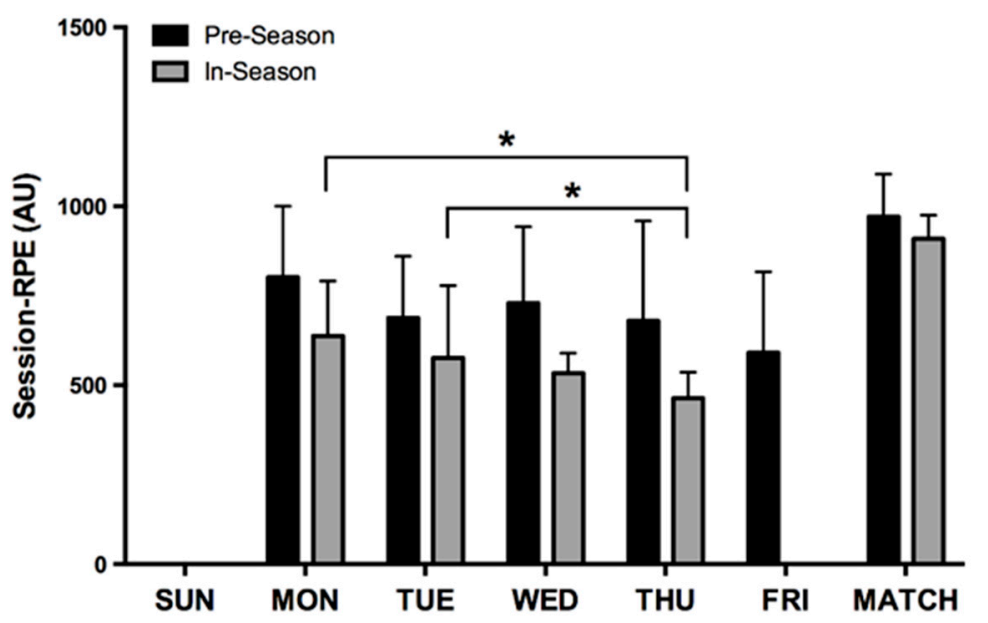

Figure 3. Daily workload during pre-season and in-season. * Significant differences.

\section{Discussion}

The aims of the present study were: (i) to analyse and describe internal and external workloads in a professional female futsal team during a whole season; (ii) to compare workloads during different periods of the season, and, (iii) to describe and compare the load profile of a typical week during pre-season and in-season periods. Based on this, the main findings of the present study were: (a) the technical-tactical training volume increased during the season, while the volume dedicated to conditional training decreased; (b) the internal load showed an oscillatory pattern in accordance with competitive periods; (c) the TWTL in mesocycle one was higher than the others followed by mesocycles two and four; (d) the workload showed a weekly periodisation with a tapering strategy during the in-season period.

The training contents showed a logical distribution in accordance with periodisation principles $[2,8,19]$, where the conditional contents were more prominent in pre-season than in the other mesocycles. During the pre-season, Teixeira et al. [8] reported 50\% of the time focused on technical-tactical contents, giving them more importance than in our study, and reporting double 
the time on power and strength. Conversely, technical-tactical tasks had more weight during the in-season mesocycles, similar to other studies, reaching over $60 \%-70 \%$ of training volume [11] or even up to $90 \%$ [20]. Strength training was one of the most important contents during the pre-season, with the sessions being reduced in volume during the subsequent mesocycles, as reported by previous authors $[11,20]$. However, as said above, other studies with professional male futsal players reported much more time dedicated to this capability during the pre-season [8], which could indicate the need to increase the volume of strength training in female futsal teams due to its relevance of sport performance. This shows some differences in contents distribution according to sex, with more relevance of strength training in men. Finally, the specific training content (technical-tactical and specific endurance tasks) seems to be the most important during the in-season period, similar to previous futsal studies $[20,21]$.

The RPE is the most-used workload tool in futsal [6-9]. The mean RPE in our study was $5.70 \pm 0.64$ over the whole season. These data are very similar to previous studies in a season with youth male players $(\mathrm{RPE}=5.5 \pm 1.7)$ [20], a professional male team $(\mathrm{RPE}=4-6)$ [21], or in different types of sessions with also professional male futsal players (physical session, $\mathrm{RPE}=5.1 \pm 0.7$, technical-tactical session, $\mathrm{RPE}=5.7 \pm 0.8$ ) [6]. However, our data are higher when compared to the study by De Freitas et al. [11] with professional male futsal players over 14 weeks (RPE $=3.3-4.3$ ). Perhaps, with the exception of the latter, the mean RPE range 5-6 points could be considered as a reference value for the daily RPE over a season in elite futsal players.

The daily workload over a season was $320 \pm 127$ AU. Scott et al. [22] found similar values for daily average on Australian professional soccer players (297 \pm 159 AU). However, Casamichana et al. [23] recorded higher values in semi-professional soccer players, with $462.4 \pm 237.9 \mathrm{AU}$, similar to data recorded for professional futsal players $500 \mathrm{AU}$ [6]. Notwithstanding, with regard to female futsal, our data are similar to previous research, which recorded an optimal training load among 350 and $450 \mathrm{AU}$ [9]. According to this issue, it could be suggested that there are no differences on the daily workload among male and female elite team sports, perhaps slightly lower in female team sports.

The mean TWTL was 2183.81 \pm 838.45 AU throughout the season. Interestingly, our data match with previous studies with high level and professional male futsal players [24,25]. Nevertheless, these studies reported lower values than others with players of the same categories [7,14]. Both studies showed a TWTL among 2000-6000 AU and 3455-5243 AU, respectively. These differences could be due to the fact that these two studies had over 8 to 10 training sessions each week, compared to our study's 5-6 sessions per week. Flat and Esco [25] recorded 2220-3000 AU in female soccer players with six training sessions per week, very similar to our findings. Thus, there seems to be a difference in total weekly workloads between sexes, likely due to the number of sessions. However, more studies are needed to validate our data as reference values for a female futsal team over a season. Finally, according to Foster [17], overtraining is more likely in weeks with workloads, monotony and strain over 4400, 2.2 and 6000, respectively. This study was performed with international competitive athletes but can be a reference of limits on workloads in sports training. In fact, similar values were only reached in our study during the second week, which highlights the relevance about managing workloads in order to reduce injury risks and optimise the conditional performance [2].

Regarding mesocycles, the workload decreased over the season, with higher loads during the first mesocycle. This matches with a study of professional female basketball players, preparing an international championship [26], and with one of the teams from the study of Teixeira et al. [8] in futsal. These increasing loads during the pre-season can accumulate higher amounts of fatigue in futsal players and, consequently, increase the injury risk $[5,14]$ due to excessive loads combined with insufficient recovery [8]. For this reason, the pre-season should be accurately designed and controlled with different tools to ensure positive adaptations on futsal players [2] as well as reducing injury risks [8]. Moreover, the second and fourth mesocycles presented higher loads than the fifth, sixth and seventh ones. These results may be explained because of the sports programming theories $[2,8,19]$, reaching higher loads on the first months, and the fourth mesocycle as a short pre-season during the in-season period [26]. However, another study found controversial results in professional female water 
polo players, with the last period of the season being the highest one, in comparison with the other three mesocycles [27]. This may be because the last phase of the season contained more intense and competitive matches, at both national and European levels. That is, the load control is fundamental to manage the athletes' physical performance determined by the goals of the team and the structure and length of the season.

During the pre-season, the sRPE did not show significant differences among the days of the week, showing only differences between Saturdays (usually friendly matches) and Tuesdays. This can be explained by the greater variability and higher loads during the pre-season period, adjusting contents to balance training and recovery to optimise conditional performance [14,18,22]. During the in-season, the weekly workload distribution is shown in previous studies $[17,28]$. That is, the sRPE decreased during the week, with higher loads on Monday (first session of the week) after a full recovery day (Sunday), and the lighter loads on Thursday, to rest for Saturday's match, as a tapering strategy, which attempts to ensure an adequate physiological response to competition [28].

Our study has some limitations as the number of external and internal load variables measured, as well as the number of players involved. More studies on professional female futsal players are needed, including more assessment tools to support these workloads, such as distance covered, the number of accelerations and decelerations, speed thresholds or changes of direction, among others. Likewise, further research should compare data from players in the First Division with lower divisions, given the differences shown by a previous study [29], as well as to include other important and specific variables in female athletes, such as the menstrual cycle and hormonal contraceptive use.

\section{Conclusions}

The present study shows the variation of training contents along the season, with the high relevance of technical-tactical tasks in a professional female futsal team with an inverse distribution of conditional volume. Likewise, workloads were higher during the pre-season mesocycles, reporting stable loads along the microcycles. During the in-season period, a tapering strategy was shown during the microcycle to achieve an optimal recovery for matches, reporting oscillatory patterns along the six mesocycles. Our findings may help to increase the knowledge about training periodisation strategies used in different contexts, such as professional female futsal teams.

\section{Practical Recommendations}

As practical application for strength and conditioning coaches and for futsal staff in general, our study highlights the need to monitor workloads along the season and to analyse the weekly loads in the proper context (pre-season vs. in-season) in elite female futsal teams. Additionally, our data could serve as a reference of a microcycle type in this sport to compare the loads reached by a team during a season and to modulate/adjust their loads according to different goals. Finally, coaches and trainers are advised to apply appropriate workloads during the pre-season (especially reducing the volume), avoiding excessive weekly loads, which are related to greater injury risks and decrement of performance [5,14]. Also, staff should define a competitive microcycle with tapering strategies to ensure optimal physical performance in matches.

Author Contributions: Conceptualisation, C.L.-F., M.M.-C. and E.R.; methodology, C.L.-F., A.P.-C., M.M.-C., and E.R.; formal analysis, C.L.-F., and A.P.-C.; investigation, C.L.-F., A.J.-L and M.M.-C.; data curation, C.L.-F.; writing — original draft preparation, C.L.-F., A.J.-L.; writing—review and editing, M.F.-V., B.T.; visualisation, A.P.-C. and A.J.-L.; supervision, B.T., E.R., M.M.-C., and M.F.-V. All authors have read and agreed to the published version of the manuscript.

Funding: This research received no external funding. Alejandro Jiménez-Loaisa was supported by the Valencian Council of Education, Research, Culture and Sports with reference ACIF/2017/155.

Acknowledgments: The authors would like to express their gratitude to the futsal players and technical staff involved in this study.

Conflicts of Interest: The authors declare no conflict of interest. 


\section{References}

1. FIFA. Women's Football Strategy. 2018. Available online: https://resources.fifa.com/image/upload/.women-sfootball-strategy.pdf?cloudid=z7w21ghir8jb9tguvbcq (accessed on 13 October 2018).

2. Vanrenterghem, J.; Nedergaard, N.J.; Robinson, M.A.; Drust, B. Training Load Monitoring in Team Sports: A Novel Framework Separating Physiological and Biomechanical Load-Adaptation Pathways. Sports Med. 2017, 47, 2135-2142. [CrossRef] [PubMed]

3. Cross, M.J.; Williams, S.; Trewartha, G.; Kemp, S.; Stokes, K.A. The Influence of In-Season Training Loads on Injury Risk in Professional Rugby Union. Int. J. Sports Physiol. Perform. 2016, 11, 350-355. [CrossRef] [PubMed]

4. Da Rocha, R.E.R.; Nunes, E.; Venera, G.D. Selective loads periodization attenuates biochemical disturbances and enhances performance in female futsal players during competitive season. Mot. Rev. Educ. Física 2015, 21, 158-167. [CrossRef]

5. Nakamura, F.Y.; Pereira, L.; Rabelo, F.N.; Flatt, A.A.; Esco, M.R.; Bertollo, M.; LoTurco, I. Monitoring weekly heart rate variability in futsal players during the preseason: The importance of maintaining high vagal activity. J. Sports Sci. 2016, 34, 2262-2268. [CrossRef]

6. Milanez, V.F.; Pedro, R.E.; Moreira, A.; Boullosa, D.; Salle-Neto, F.; Nakamura, F.Y. The Role of Aerobic Fitness on Session Rating of Perceived Exertion in Futsal Players. Int. J. Sports Physiol. Perform. 2011, 6, 358-366. [CrossRef]

7. Moreira, A.; De Moura, N.R.; Coutts, A.; Costa, E.C.; Kempton, T.; Aoki, M.S. Monitoring Internal Training Load and Mucosal Immune Responses in Futsal Athletes. J. Strength Cond. Res. 2013, 27, 1253-1259. [CrossRef]

8. Teixeira, A.S.; Nunes, R.F.H.; Yanci, J.; Izzicupo, P.; Flores, L.J.F.; Romano, J.C.; Guglielmo, L.G.A.; Nakamura, F.Y. Different Pathways Leading up to the Same Futsal Competition: Individual and Inter-Team Variability in Loading Patterns and Preseason Training Adaptations. Sports 2018, 7, 7. [CrossRef]

9. Wilke, C.F.; Ramos, G.P.; Pacheco, D.A.; Santos, W.H.; Diniz, M.S.; Gonçalves, G.G.; Marins, J.C.; Wanner, S.; Silami-Garcia, E. Metabolic Demand and Internal Training Load in Technical-Tactical Training Sessions of Professional Futsal Players. J. Strength Cond. Res. 2016, 30, 2330-2340. [CrossRef]

10. Haddad, M.; Stylianides, G.; Djaoui, L.; Dellal, A.; Chamari, K. Session-RPE Method for Training Load Monitoring: Validity, Ecological Usefulness, and Influencing Factors. Front. Mol. Neurosci. 2017, 11. [CrossRef]

11. de Freitas, V.H.; Miloski, B.; Bara Filho, M.G. Quantification of training load using session RPE method and performance in futsal. Rev. Bras. Cineantropometria Desempenho Hum. 2012, 14, 73-82.

12. Miloski, B.; de Freitas, V.; Bara Filho, M.G. Monitoring of the internal training load in futsal players over a season. Rev. Bras. Cineantropometria Desempenho Hum. 2012, 14, 671-967.

13. Clemente, F.M.; Nikolaidis, P.T. Profile of 1-month training load in male and female football and futsal players. SpringerPlus 2016, 5, 694. [CrossRef] [PubMed]

14. Nakamura, F.Y; Pereira, L.; Rabelo, F.N.; Ramirez-Campillo, R.; LoTurco, I. Faster Futsal Players Perceive Higher Training Loads and Present Greater Decreases in Sprinting Speed During the Preseason. J. Strength Cond. Res. 2016, 30, 1553-1562. [CrossRef] [PubMed]

15. Álvarez Medina, J.; Murillo Lorente, V. Comparison of planned and executed loads in futsal training: The double scale. RETOSNuevas Tendencias en Educ Física Deport y Recreación 2016, 29, 48-52.

16. Borg, G. Borgs Perceived Exertion and Pain Scales; Human Kinetics: Champaign, IL, USA, 1998.

17. Foster, C. Monitoring training in athletes with reference to overtraining syndrome. Med. Sci. Sports Exerc. 1998, 30, 1164-1168. [CrossRef]

18. Batterham, A.; Hopkins, W.G. Making Meaningful Inferences About Magnitudes. Int. J. Sports Physiol. Perform. 2006, 1, 50-57. [CrossRef]

19. Coyne, J.O.C.; Haff, G.G.; Coutts, A.J.; Newton, R.; Nimphius, S. The Current State of Subjective Training Load Monitoring - a Practical Perspective and Call to Action. Sports Med.-Open 2018, 4, 58. [CrossRef]

20. Rabelo, F.N.; Pasquarelli, B.N.; Gonçalves, B.; Matzenbacher, F.; Campos, F.A.D.; Sampaio, J.; Nakamura, F.Y. Monitoring the Intended and Perceived Training Load of a Professional Futsal Team Over 45 Weeks. J. Strength Cond. Res. 2016, 30, 134-140. [CrossRef] 
21. Scott, B.; Lockie, R.G.; Knight, T.J.; Clark, A.C.; De Jonge, X.J. A Comparison of Methods to Quantify the In-Season Training Load of Professional Soccer Players. Int. J. Sports Physiol. Perform. 2013, 8, 195-202. [CrossRef]

22. Casamichana, D.; Castellano, J.; Calleja-González, J.; Román, J.S.; Castagna, C. Relationship Between Indicators of Training Load in Soccer Players. J. Strength Cond. Res. 2013, 27, 369-374. [CrossRef]

23. Moreira, A.; McGuigan, M.R.; Arruda, A.; Freitas, C.G.; Aoki, M.S. Monitoring Internal Load Parameters During Simulated and Official Basketball Matches. J. Strength Cond. Res. 2012, 26, 861-866. [CrossRef] [PubMed]

24. Flatt, A.A.; Esco, M.R. Smartphone-Derived Heart-Rate Variability and Training Load in a Women's Soccer Team. Int. J. Sports Physiol. Perform. 2015, 10, 994-1000. [CrossRef]

25. Nunes, J.A.; Moreira, A.; Crewther, B.T.; Nosaka, K.; Viveiros, L.; Aoki, M.S. Monitoring Training Load, Recovery-Stress State, Immune-Endocrine Responses, and Physical Performance in Elite Female Basketball Players During a Periodized Training Program. J. Strength Cond. Res. 2014, 28, 2973-2980. [CrossRef] [PubMed]

26. Varamenti, E.I.; Kyparos, A.; Veskoukis, A.S.; Bakou, M.; Kalaboka, S.; Jamurtas, A.Z.; Koutedakis, Y.; Kouretas, D. Oxidative stress, inflammation and angiogenesis markers in elite female water polo athletes throughout a season. Food Chem. Toxicol. 2013, 61, 3-8. [CrossRef] [PubMed]

27. Milanez, V.F.; Ramos, S.P.; Okuno, N.M.; Boullosa, D.A.; Nakamura, F.Y. Evidence of a Non-Linear Dose-Response Relationship between Training Load and Stress Markers in Elite Female Futsal Players. J. Sports Sci. Med. 2014, 13, 22-29.

28. Impellizzeri, F.M.; Rampinini, E.; Coutts, A.J.; Sassi, A.; Marcora, S. Use of RPE-Based Training Load in Soccer. Med. Sci. Sports Exerc. 2004, 36, 1042-1047. [CrossRef]

29. Ramos-Campo, D.J.; Rubio-Arias, J.Á.; Carrasco-Poyatos, M.; Alcaraz, P.E. Physical performance of elite and subelite Spanish female futsal players. Biol. Sport 2016, 33, 297-304. [CrossRef]

(C) 2020 by the authors. Licensee MDPI, Basel, Switzerland. This article is an open access article distributed under the terms and conditions of the Creative Commons Attribution (CC BY) license (http://creativecommons.org/licenses/by/4.0/). 